\title{
How Gender Identity and Transgender Status Affect Perceptions of Attractiveness
}

\author{
Jessica M. Mao ${ }^{1}$, M. L. Haupert ${ }^{1,2}$, and Eliot R. Smith ${ }^{1}$
}

${ }^{1}$ Department of Psychological and Brain Sciences, Indiana University, Bloomington, IN USA

${ }^{2}$ The Kinsey Institute, Indiana University, Bloomington, IN USA

Corresponding Author: Eliot R. Smith, Department of Psychological and Brain Sciences, Indiana University, Bloomington, IN, esmith4@indiana.edu

\section{Author Note:}

This article is based on an honors thesis project by the first author, supervised by the second and third authors. We thank Justin Garcia and Dale Sengelaub for their support of the thesis, and Eric Budzielek and Gwendolyn Evans for research assistance. 
GENDER LABELS AND ATTRACTIVENESS 2

\begin{abstract}
Can a perceiver's belief about a target's transgender status (distinct from gender nonconforming appearance) affect perceptions of the target's attractiveness? Cisgender, heterosexual men and women $(\mathrm{N}=319)$ received randomly assigned labels (cisgender cross-gender, transgender man, transgender woman, or non-binary) paired with 48 cross-sex targets represented by photos, and rated the attractiveness and related characteristics of those targets. The gender identity labels had a strong, pervasive effect on ratings of attraction. Non-binary and especially transgender targets were perceived as less attractive than cisgender targets. The effect was particularly strong for male perceivers, and for women with traditional gender attitudes. Sexual and romantic attraction are not driven solely by sexed appearance; information about gender identity and transgender status also influences these assessments. These results have important implications for theoretical models of sexual orientation and the dating lives of transgender people.
\end{abstract}




\section{How Gender Identity and Transgender Status Affect Perceptions of Attractiveness}

Around 1.4 million U.S. adults identify as transgender (Flores et al., 2016). The transgender community has recently gained visibility from media attention to transgender celebrities like Laverne Cox and Caitlyn Jenner (Bissenger \& Leibovitz, 2015; Steinmetz, 2014), and debates about transgender people's bathroom usage (e.g. Berman \& Phillips, 2017; ACLU, 2017). However, transgender individuals are not necessarily visible as such to the people around them. Over half the respondents to the US Trans Survey (James et al., 2016) reported that they almost always "pass" as cisgender, and only about $30 \%$ of the US population reports knowing someone who is transgender (Martinez et al., 2016). These numbers suggest that many cisgender people interact with transgender people while assuming they are cisgender. How does knowledge about someone's transgender status affect others' perceptions of and willingness to interact with the person?

The prevalence of "passing" has often been overlooked by the literature on perceptions of transgender people (e.g. Hill \& Willoughby, 2005; Walch et al., 2012), which tends to conflate a person's transgender status with physical gender non-conformity. However, these dimensions are conceptually and experientially distinct. For example, many cisgender people (e.g. lesbians) are perceived as gender non-conforming, while many transgender people conform to the gender with which they identify. Gender-conforming transgender people risk experiencing discrimination (barring intersecting marginalized identities) primarily from revealing their transgender status (Serano, 2007), so many simply do not disclose their transgender status.

Revealing one's status can affect even basic social interaction, influencing others' interest in friendship or dating. In fact, the issue of when (if ever) to disclose one's trans status to potential relationship partners is controversial within the transgender community. Disclosing 
trans status after a relationship has already begun carries risks; if the disclosure is not wellreceived, it may mean losing the relationship, or even exposing oneself to violence. Transgender people (especially people of color) are at higher risk of intimate partner violence (Dank et al., 2014; James et al., 2016), and perpetrators have often tried to use their victims' trans status to legitimize the violence (Lee \& Kwan, 2014; Wodda \& Panfil, 2015). Disclosing trans status early in a relationship may avoid some of these risks, but many trans people feel that their trans status is private and personal (Belawski \& Sojka, 2014). Immediate disclosure may also risk shrinking a transgender person's pool of potential partners. A large majority $(>75 \%)$ of the general population report that they would not be willing to date a transgender person (Bame, 2017), and some transgender authors report that previously-interested potential partners sometimes lose interest in them upon learning that they are transgender (e.g. Serano, 2007). Clearly, the choice of whether and when to disclose transgender status is a complex one.

These issues come clearly into focus when one considers dating websites such as OKCupid (OKCupid, 2017). With the recent addition of multiple gender options (including transgender and non-binary) on many dating websites, users have many choices about how to portray their gender identity and transgender status to prospective partners. Perceivers examining dating profiles obtain gender identity and trans status information immediately (as labels in a target's profile) rather than learning or guessing such information during a relationship. However, the effects of this immediate disclosure remain unclear. How will transgender or non-binary ${ }^{1}$ labels (compared to cisgender) affect perceivers' reactions?

Only two existing studies have assessed sexual attraction to transgender people (Gerhardstein \& Anderson, 2010; Stern \& Rule, 2017) but both have significant limitations.

\footnotetext{
${ }^{1}$ A gender identity other than man or woman.
} 
Gerhardstein and Anderson studied attraction to one male and one female stimulus photo labeled as a trans man or a trans woman respectively, plus each photo altered to have gendernonconforming appearance. Stern and Rule measured attraction to photos of men and women varying in gender-conforming appearance. While they used stimulus photos of transgender people, photos were unlabeled so we cannot tell whether participants perceived them as cisgender or transgender. As neither study compared reactions to photos labeled as trans to photos labeled as cis, and neither examined non-binary labels at all, they do not suggest specific hypotheses for our study.

On theoretical grounds, we might anticipate that sexual attraction ratings will be predicted by sexual orientation, as most definitions of sexual orientation include sexual attraction as a primary component (e.g. Sell, 1997; Rosario \& Schrimshaw, 2014; Bailey et al., 2016; Wolff et al., 2017). For example, Rosario \& Schrimshaw (2014) define sexual attraction as "the internal component of sexual orientation" which they argue is "independent of whatever pressure may be applied by any external force (e.g. family, religion, culture) for one to be attracted to one or the other sex" and "not under the control of the individual" (p. 556). Most models of sexual orientation argue that it is "oriented" to some essential facet of a target's gender, almost always biological sex (Bailey et al., 2016). However, van Anders (2015) notes that virtually no empirical evidence exists for the idea that sexual attraction is toward "biological sex" (i.e. gonads, genitals, chromosomes, and hormones) rather than gender identity, sexed appearance, or some combination of these factors. As these characteristics are typically aligned in cisgender populations, the terms "sex" and "gender" as used in conceptualizations of sexual orientation have almost never been carefully operationally defined, nor have the influences of these factors been separately measured. Our study design allows us to do so. 
We advance four competing hypotheses about attraction to transgender people based on prior theory (see Table 1). The first three assume that attraction to transgender people can be predicted from sexual orientation alone, but assume different targets for this orientation (i.e. "biological sex," gender identity, or sexed appearance). The fourth hypothesis (which we favor) proposes that attraction ratings of transgender people reflect both sexual orientation (including any or all of the above factors) and prejudice toward transgender people. If this hypothesis is supported, it will provide evidence that future research on sexual orientation must more precisely define this construct and perhaps also reexamine the frequent assumption that self-reports of this construct are not subject to social influence.

Table 1

Hypotheses about the Effects of Transgender Labels on Ratings of Sexual Attraction

\begin{tabular}{|c|c|c|}
\hline $\begin{array}{l}\text { Possible Predictors } \\
\text { of Attraction Ratings }\end{array}$ & Evidence from Previous Research & $\begin{array}{l}\text { Expected Pattern } \\
\text { of Results }\end{array}$ \\
\hline $\begin{array}{l}\text { Hypothesis 1: } \\
\text { Attraction ratings can } \\
\text { be fully predicted by } \\
\text { sexual orientation } \\
\text { (defined as oriented to } \\
\text { "biological sex" or sex } \\
\text { assigned at birth). }\end{array}$ & $\begin{array}{l}\text { Virtually all researchers to date define sexual } \\
\text { orientation and attraction as oriented to } \\
\text { biological sex (e.g. Sell, 1997; Rosario \& } \\
\text { Schrimshaw, 2014; Bailey et al., 2016; Wolff } \\
\text { et al., 2017). However, van Anders (2015) } \\
\text { argues that "biological sex" here is poorly } \\
\text { defined and measured; sex assigned at birth is } \\
\text { usually substituted because researchers lack } \\
\text { information about gonads, genitals, } \\
\text { chromosomes, and hormones (though medical } \\
\text { intervention can change many of these). }\end{array}$ & $\begin{array}{l}\text { Heterosexual men } \\
\text { will express equal } \\
\text { attraction to } \\
\text { cisgender women } \\
\text { and transgender } \\
\text { men. Heterosexual } \\
\text { women will express } \\
\text { equal attraction to } \\
\text { cisgender men and } \\
\text { transgender women. }\end{array}$ \\
\hline $\begin{array}{l}\text { Hypothesis 2: } \\
\text { Attraction ratings can } \\
\text { be fully predicted by } \\
\text { sexual orientation } \\
\text { (defined as oriented to } \\
\text { gender identity). }\end{array}$ & $\begin{array}{l}\text { van Anders (2015) proposes gender identity } \\
\text { as one of many possible gendered } \\
\text { characteristics to which one might be sexually } \\
\text { attracted, a perspective which also appears in } \\
\text { qualitative studies with transgender and non- } \\
\text { binary participants (e.g. Nagoshi et al., 2014; } \\
\text { Galupo et al., 2016). This pattern might also } \\
\text { emerge if sexual orientation is based on } \\
\text { biological sex and perceivers assume that } \\
\text { transgender people usually alter their } \\
\text { biological sex. }\end{array}$ & $\begin{array}{l}\text { Heterosexual men } \\
\text { will express equal } \\
\text { attraction to } \\
\text { cisgender and } \\
\text { transgender women. } \\
\text { Heterosexual } \\
\text { women will express } \\
\text { equal attraction to } \\
\text { cisgender and } \\
\text { transgender men. }\end{array}$ \\
\hline
\end{tabular}




\begin{tabular}{|c|c|c|}
\hline $\begin{array}{l}\text { Hypothesis 3: } \\
\text { Attraction ratings can } \\
\text { be fully predicted by } \\
\text { sexual orientation } \\
\text { (defined as oriented to } \\
\text { sexed appearance). }\end{array}$ & $\begin{array}{l}\text { van Anders (2015) proposes sexed apperance } \\
\text { as one of many possible gendered } \\
\text { characteristics to which one might be sexually } \\
\text { attracted, a perspective which also appears in } \\
\text { qualitative studies with transgender and non- } \\
\text { binary participants (e.g. Nagoshi et al., 2014; } \\
\text { Galupo et al., 2016). Of note, our stimuli are } \\
\text { pretested to have equivalently } \\
\text { masculine/feminine appearance, so sexed } \\
\text { appearance is held constant in our design. }\end{array}$ & $\begin{array}{l}\text { Heterosexual men } \\
\text { will express equal } \\
\text { attraction to all } \\
\text { female-appearing } \\
\text { targets (i.e. all } \\
\text { stimuli to which } \\
\text { they are exposed in } \\
\text { our study). } \\
\text { Heterosexual } \\
\text { women will express } \\
\text { equal attraction to } \\
\text { all male-appearing } \\
\text { targets (i.e. all } \\
\text { stimuli). }\end{array}$ \\
\hline $\begin{array}{l}\text { Hypothesis 4: } \\
\text { Attraction ratings can } \\
\text { be partially predicted } \\
\text { by sexual orientation } \\
\text { (influenced by a } \\
\text { combination of sex } \\
\text { assigned at birth, } \\
\text { gender identity, and } \\
\text { sexed appearance) but } \\
\text { also are influenced by } \\
\text { prejudice. }\end{array}$ & $\begin{array}{l}\text { van Anders (2015) proposes that sexual } \\
\text { attraction may incorporate aspects of sexed } \\
\text { appearance, biological sex, and gender } \\
\text { identity, and that these characteristics may } \\
\text { vary in importance from person to person. } \\
\text { However, we also expect that negative } \\
\text { attitudes and/or prejudice toward transgender } \\
\text { people may cause participants to express less } \\
\text { attraction to trans targets than cis targets. In } \\
\text { addition, some research suggests that many } \\
\text { heterosexual perceivers fear that attraction to } \\
\text { transgender targets will cause them to be } \\
\text { perceived as homosexual (Bettcher, 2007) } \\
\text { and/or view such targets as challenging } \\
\text { cultural assumptions that gender is binary } \\
\text { (Garfinkel, 1967; Kessler \& McKenna, 1978; } \\
\text { Nagoshi et al. 2008), meaning that attraction } \\
\text { to transgender people may pose an additional } \\
\text { threat. In this case, ratings of sexual attraction } \\
\text { may reflect something besides the purportedly } \\
\text { internal, uncontrollable influence of sexual } \\
\text { orientation as described by most existing } \\
\text { theories (e.g. Rosario \& Schrimshaw, 2014). }\end{array}$ & $\begin{array}{l}\text { Heterosexual men } \\
\text { will express less } \\
\text { attraction to } \\
\text { transgender men and } \\
\text { women than to } \\
\text { cisgender women. } \\
\text { Heterosexual } \\
\text { women will express } \\
\text { less attraction to } \\
\text { transgender men and } \\
\text { women than to } \\
\text { cisgender women. } \\
\text { Participants with } \\
\text { high gender } \\
\text { traditionalism will } \\
\text { express less } \\
\text { attraction to } \\
\text { transgender people } \\
\text { than participants } \\
\text { with low gender } \\
\text { traditionalism. }\end{array}$ \\
\hline
\end{tabular}

While transgender identities are increasingly recognized, non-binary gender identities have been largely ignored by academics, so there is even less existing work on which to base hypotheses about reactions to non-binary targets compared to transgender targets (but see Factor \& Rothblum, 2008; Kuper, Nussbaum, \& Mustanski, 2012; Tate, Youssef, \& Bettergarcia, 2014; 
van Anders, 2015). Virtually nothing is known about how these labels influence perceptions of attractiveness. Indeed, attraction to non-binary people is impossible to express in standard conceptualizations of sexual orientation because homosexual, heterosexual, and bisexual refer to attraction to specific gendered categories of people (van Anders, 2015). We suggest two competing hypotheses about the effects of non-binary labels (Table 2).

Table 2

Hypotheses about the Effects of a Non-binary Label on Ratings of Sexual Attraction

\begin{tabular}{|l|l|}
\hline Hypothesis 1 & $\begin{array}{l}\text { If transgender targets are seen as less attractive because they challenge } \\
\text { cultural conceptions of gender, non-binary targets will be viewed even } \\
\text { more negatively. After all, a transgender person might be seen as simply } \\
\text { having been miscategorized, posing a less fundamental challenge to binary } \\
\text { conceptions of gender than an explicit rejection of the gender binary. }\end{array}$ \\
\hline Hypothesis 2 & $\begin{array}{l}\text { If perceivers understand non-binary identity as conveying relatively } \\
\text { shallow information, this label might lead to less negative reactions than a } \\
\text { transgender label. A female-appearing person identifying as non-binary } \\
\text { might be understood, for example, as merely a woman who rejects female- } \\
\text { stereotypic clothing, activities, or mannerisms. }\end{array}$ \\
\hline
\end{tabular}

Our study will shed light on these issues by revealing patterns of attraction to targets labeled as cisgender, transgender, and non-binary. To further understand the potential reasons behind participants' reactions, we measured transphobia and several highly-correlated constructs: Homophobia, gender essentialism, Right-Wing Authoritarianism, and Fundamentalism (e.g. Hill \& Willoughby, 2005; Tee \& Hegarty, 2006; Nagoshi et al., 2008; Norton \& Herek, 2013). Because these variables may be associated with endorsement of the idea that gender is binary and unchanging (Garfinkel, 1967; Kessler \& McKenna, 1978; Nagoshi et al. 2008), we expect that participants with higher scores on these scales may give more negative ratings to transgender and non-binary targets. 
By determining how transgender status and non-binary gender identity labels influence the perceived attractiveness of targets, this research provides the first experimental evidence about attraction to transgender and non-binary people in comparison to cis people.

\section{Methodological Considerations}

Avoiding appearance confounds. We seek to examine the unique effects of gender identity and transgender status while avoiding confounds related to gender-conforming appearance, yielding results that are generalizable to the many gender-conforming transgender people (James et al., 2016). Study designs that present photos of actual cis and trans targets with corresponding gender identity labels leave gender-conforming appearance uncontrolled, possibly introducing a confound. Designs that present photos of targets varying in gender conformity but without cis or trans labels also cannot assess the unique effect of perceived gender identity independent of appearance (e.g., Stern \& Rule, 2017). Our study uses a fixed set of stimulus photos, each presented with different gender identity labels to different subsets of participants (counterbalanced). Thus, across participants, there is no confounding between genderconforming appearance (or other characteristics of the photos) and gender identity label. Secondarily, this study design lets us investigate whether knowledge of transgender status can influence perceptions of gender non-conformity. For example, do participants see a woman's face as less feminine when they believe she is a transgender woman?

Number of stimuli and statistical power. The number of photo stimuli is critical for generalizability. Using a small number of stimuli reduces statistical power (which depends on number of stimuli and participants; Judd, Westfall, \& Kenny, 2012; Westfall, Kenny, \& Judd, 2014). Using few stimuli also inherently introduces confounds, because they are bound to differ in irrelevant ways. Most important, using an adequate number of stimulus photos and treating 
photos as a random factor in the analysis are essential for statistical generalization beyond the tested stimuli, to the population of other similar stimuli. This is exactly the type of generalization across participants that researchers seek by using many participants and treating participants as a random factor in the analysis (Judd et al., 2012). Relevant previous studies have used extremely limited numbers of stimulus photos; both Gerhardstein and Anderson (2010) and Stern and Rule (2010) used only four photos. The very small numbers of targets in these studies cripples statistical power.

\section{Method}

This study evaluates cisgender, heterosexual males' and females' perceptions of sexual/romantic attractiveness of individuals labeled as cisgender, transgender and non-binary.

\section{Participants}

We collected data from 342 self-identified cisgender heterosexual students, and excluded 13 who self-reported non-heterosexual orientation. ${ }^{2}$ Ten more did not complete the online questionnaire, leaving a final $\mathrm{N}$ of 319 (95 men and 224 women). We made no other data exclusions; however, Ns for specific analyses vary slightly due to participants who failed to respond to specific items.

Our $\mathrm{N}$ was determined by the mid-semester data collection deadline for undergraduate theses. We did not conduct an a priori power analysis because Gerhardstein and Anderson (2010) did not compare cis and trans targets or consider stimuli as a random factor, and therefore offer insufficient information to estimate the effect size for the key comparison in our design. A post-hoc power analysis for hierarchical designs (Westfall et al., 2014) found that with our design, power to detect a small effect $(\mathrm{d}=0.2)$ is approximately .82. Power for the effect sizes

\footnotetext{
${ }^{2}$ While ratings by transgender and non-heterosexual judges would also be interesting, we could not practically recruit adequate numbers.
} 
we observed (e.g., mean difference between rated attractiveness of cis and trans women, $\mathrm{d}=.49$ ) is close to $100 \%$.

\section{Materials}

We obtained stimuli from the Chicago Face Database (Ma, Correll, \& Wittenbrink, 2015), selecting 48 male and 48 female photos that were rated high in masculinity or femininity, respectively. We avoided using faces whose gender appeared ambiguous to ensure that we did not conflate transgender status with gender non-conformity. Our sample of faces was racially diverse, to better approximate the general population compared to an all-White sample. For each gender, we had 28 White, 8 Black, 8 Latinx, and 4 Asian faces.

Male participants saw and rated all 48 female photos, while female participants saw and rated all 48 male photos. Each photo was presented as an online dating profile, together with a gender identity label (cisgender woman/man for the female/male photos respectively, nonbinary, trans man, or trans woman) and a racial label (Asian, Black, Latinx, or White). The race label always matched the race of the face, while the gender label was counterbalanced such that each photo was presented an approximately equal number of times with each label (for different participants).

\section{Procedure}

Before the rating task, participants were given definitions of the terms "cisgender," "transgender," and "non-binary." For consistency, we gave similarly detailed definitions of the racial categories (definitions in Supplemental Materials). Then the 48 stimuli (photo plus gender and race labels) were presented in random order. For each stimulus, participants indicated how masculine to feminine they perceived the individual to be, their level of sexual attraction and romantic attraction towards the individual, and whether they would be willing to become friends 
with, and willing to go on a date with the individual (see Figure 1). Masculinity/femininity and attraction were measured with sliders on 0-100 scales, and willingness to befriend and date using responses of yes/maybe/no, recoded to $0=$ no, $0.5=$ maybe, $1=$ yes. 


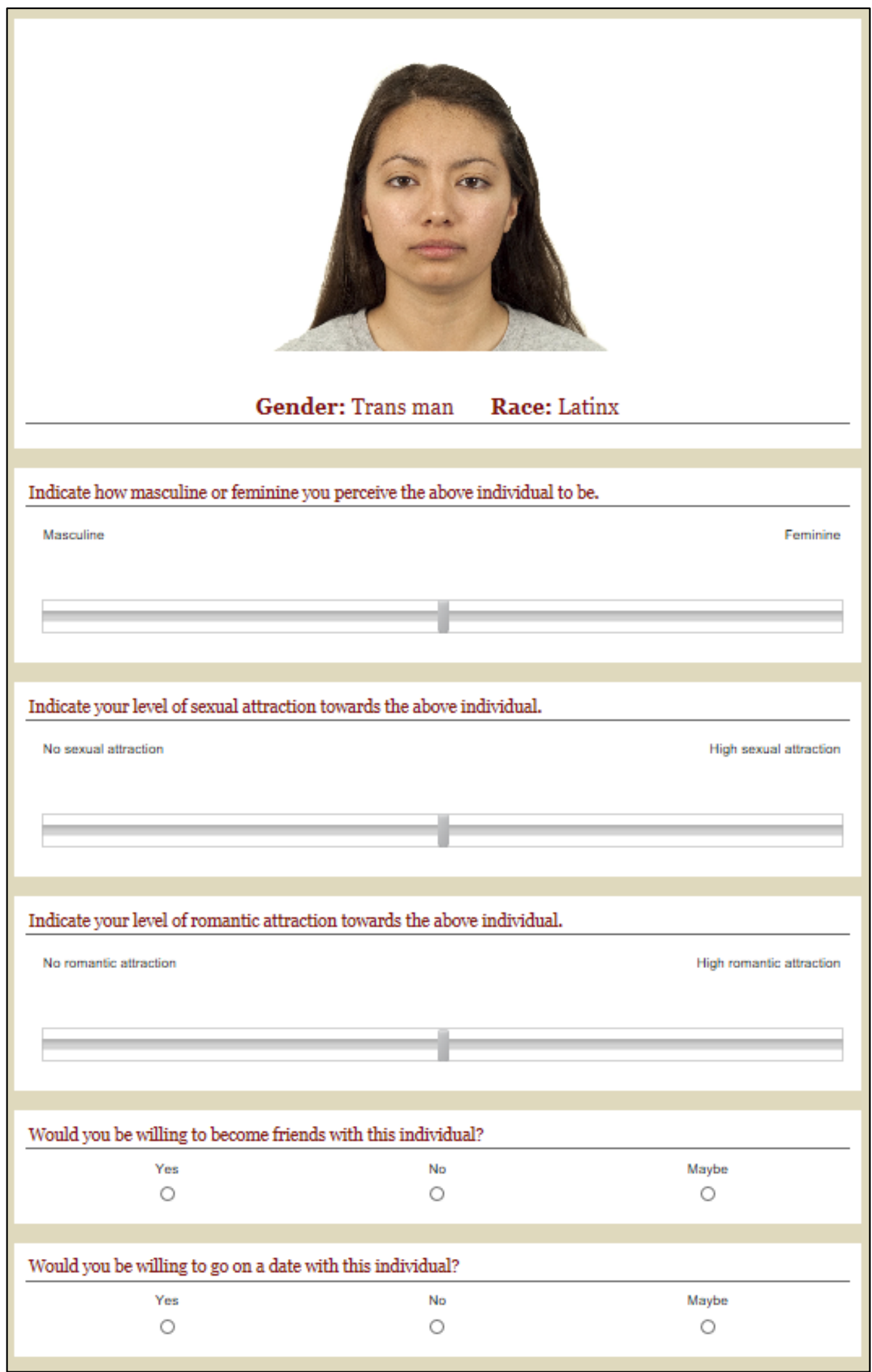

Figure 1. Example stimulus presentation with dependent variables. 
Following the photo ratings, participants completed individual difference measures as potential moderators. Gerhardstein and Anderson (2010) found that transphobia and homophobia correlated with ratings of transgender targets, so we measured these constructs. We included two measures of each because it is unclear which is better (Genderism and Transphobia by Hill \& Willoughby, 2005; Transphobia by Nagoshi et al., 2008); Homophobia by Wright, Adams, \& Bernat, 1999; Modern Homonegativity by Morrison \& Morrison, 2003). We also measured right-wing authoritarianism (Mangaelli et al., 2007) and religious fundamentalism (Altemeyer \& Hunsberger, 2004), which are often found to correlate with prejudice in general. We measured gender essentialism (Haupert, 2016) ${ }^{3}$ because a belief that gender is inborn and unchanging is logically one potential source of negative feelings about trans people. ${ }^{4}$ All items used 7-point Likert scales from "Strongly Disagree" to "Strongly Agree."

After completing these scales, participants completed additional demographic questions including their age, religion, political party, etc. These were not used in our analyses and are listed in supplemental materials.

\section{Results}

\section{Analysis}

The hierarchical linear model analyses used the R function lmer (https://cran.rproject.org/web/packages/lme4/lme4.pdf). The fixed effects tested were gender label, participant gender, and target race, plus all their interactions. The model included random effects for participant and photo, with random intercepts and slopes for label by participant, and random intercepts and slopes for label by photo. The Satterthwaite approximation was used for degrees

\footnotetext{
${ }^{3}$ See Supplemental Materials for item wording.

${ }^{4}$ As a construct validation exercise for the new gender essentialism measure, the Moral Foundations Questionnaire (Graham et al., 2011) and Ambivalent Sexism Inventory- Short Form (Glick \& Whitehead, 2010) were also included in the study. We did not expect these to moderate our effects of interest.
} 
of freedom for significance tests (the lmerTest package, https://cran.rproject.org/web/packages/lmerTest/lmerTest.pdf); this usually results in fractional denominator df values. R code for the model is included in supplemental materials.

Sexual and romantic attraction and wanting as date. For sexual attraction, there were main effects of label $(F(3,188.88)=40.96, p<.001)$ and participant gender $(F(1,179.31)=10.07$, $\mathrm{p}=.002)$. The label $*$ participant gender interaction was significant with $\mathrm{F}(3,188.88)=15.98$, $p<.001$. The effect (Figure 2) had the same pattern for male and female participants: compared to cis targets, non-binary targets were rated lower and both trans categories lower still. The effect was stronger for males than for female participants. For each participant gender, all pairwise differences between the simple means for labels are significant at $\mathrm{p}<.05$. Of specific interest, for the two trans labels, male participants rated trans women higher than trans men, mean difference $=-2.6, \mathrm{t}(142.2)=-2.82, \mathrm{p}=.005, \mathrm{CI}(-4.36,-.77)$. For female participants the reverse was true $($ difference $=2.7, t(69.2)=3.70, \mathrm{p}<.001, \mathrm{CI}(1.25,4.16))$. This could be because participants consider gender identity (and not just appearance) when determining their attraction to a target, or because participants dislike a mismatch between gender identity and photo appearance (e.g., female photos labeled as trans men). This same interaction of participant gender * gender of trans-labeled photos was found by Gerhardstein and Anderson (2010).

The label * participant gender interaction was also found for romantic attraction $(\mathrm{F}(3$, $159.64)=12.34, \mathrm{p}<.001)$ and for wanting to date the target $(\mathrm{F}(3,163.67)=13.07, \mathrm{p}<.001)$. The patterns of means were very similar to those for sexual attraction. Graphs and detailed results for these two dependent variables are in supplemental materials. For all three of these dependent variables, target race had no significant main effects or interactions. 


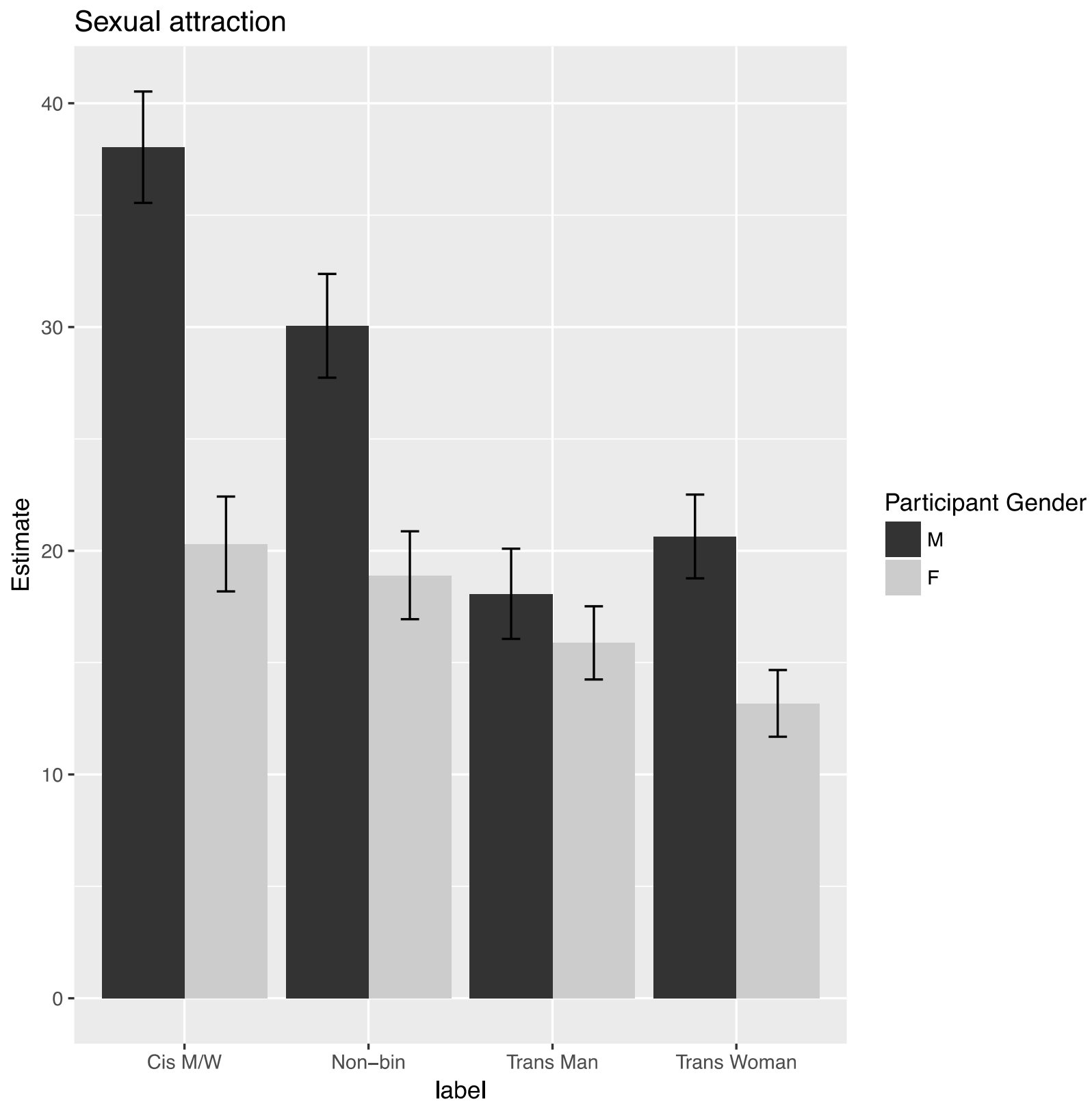

Figure 2. Means for participant gender* label interaction for sexual attraction. Error bars represent standard errors. "Cis $\mathrm{M} / \mathrm{W}$ " refers to targets identified as cisgender men (for female participants) or cisgender women (for male participants). 
Wanting as friend. There was a participant gender * label interaction $(\mathrm{F}(3,176.66)=10.03, \mathrm{p}<.001)$ for wanting as a friend. Means had the same pattern as the other dependent variables for male participants, but there was virtually no label effect for females (Figure 3). Thus, female participants are equally willing to befriend cis, non-binary, and trans individuals. In contrast, men show the same pattern for ratings of friendship as participants of both genders do for sexual and romantic attraction: preferring cis over non-binary and nonbinary over trans targets. This finding is consistent with men's tendency to sexualize cross-sex friendships more than women (e.g. Abbey, 1982; Bleske-Rechek et al., 2012). Again, target race did not have significant main effects or interactions. 


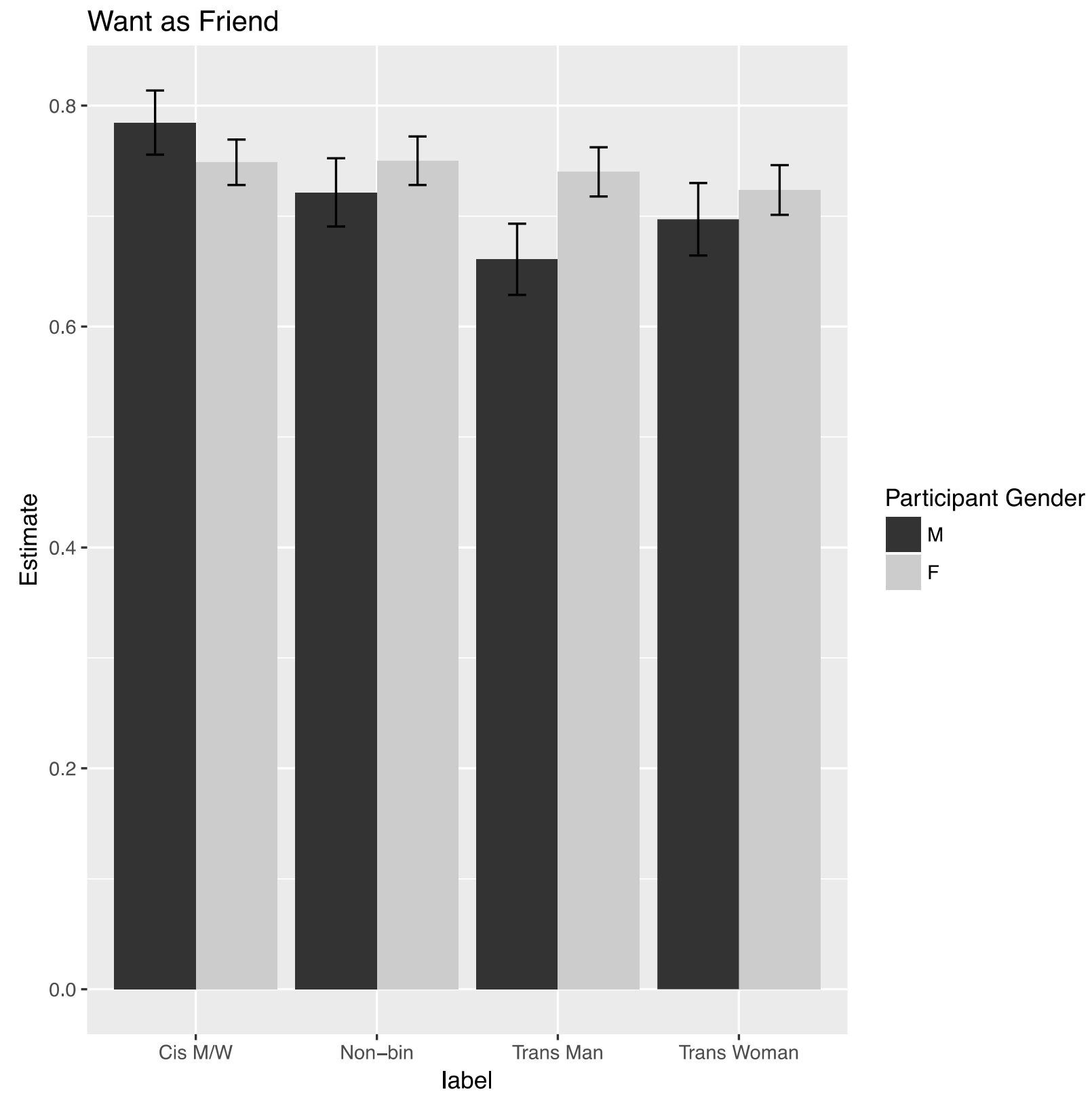

Figure 3. Means for participant gender * label interaction for desiring as friend. Error bars represent standard errors. "Cis $\mathrm{M} / \mathrm{W}$ " refers to targets identified as cisgender men (for female participants) or cisgender women (for male participants). 
Masculinity/femininity. Though not a major focus of this study, our design permits us to examine effects of gender identity labels on perceived masculinity/femininity of the target photos. As expected, this rating showed an extremely strong main effect of participant gender because male participants viewed female photos and vice versa: $F(1,328.5)=281.0, p<.001$. Males gave ratings averaging 61.2 and females 25.5 on the $0-100$ scale (Figure 4). There was also an interaction of participant gender * label $(\mathrm{F}(3,213.19)=32.95, \mathrm{p}<.001)$. Targets labeled as non-binary or (especially) transgender, compared to those labeled cisgender, were rated less gender-typical. That is, male photos labeled transgender were rated less masculine than cis male photos, and female photos labeled transgender were rated less feminine than cis female photos. Target race $(\mathrm{F}(3,87.55)=5.20, \mathrm{p}=.002)$ also significantly affected this measure. Asian and White photos (least squares means $(\mathrm{CIs})=46.1(42.1,50.1)$ and $45.3(43.1,47.4))$ were rated more feminine than Black and Latinx photos $(40.8(37.7,43.8)$ and $41.1(38.1,44.2))$. The Asian and White means did not differ significantly, nor did the Black and Latinx means, but all other comparisons were significant at $\mathrm{p}<.05$. 


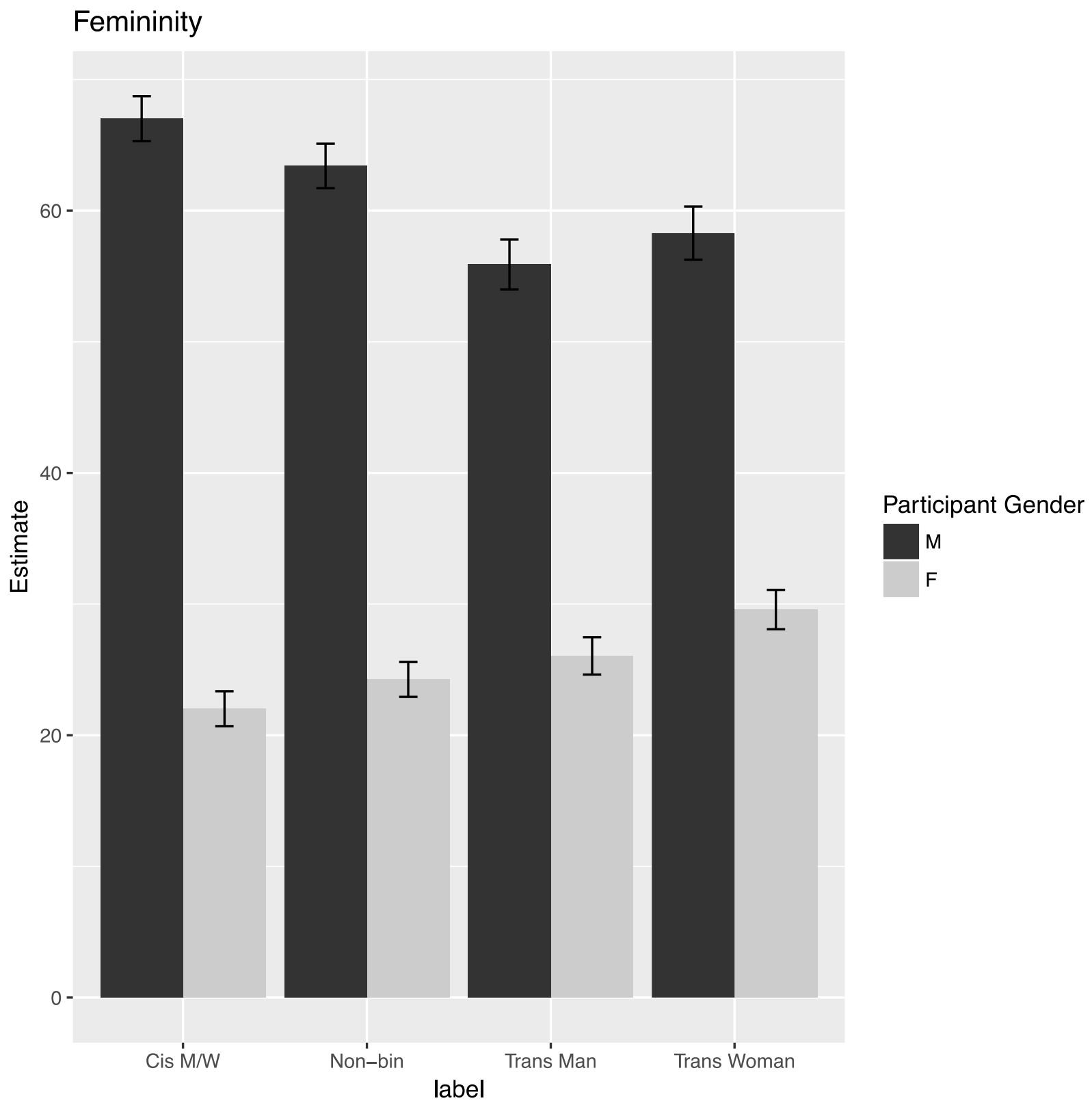

Figure 4. Means for participant gender * label interaction for perceived femininity of face.

Error bars represent standard errors. "Cis $\mathrm{M} / \mathrm{W}$ " refers to targets identified as cisgender men (for female participants) or cisgender women (for male participants). 


\section{Moderator Analyses}

Do individual differences in views about gender in general (or transgender people in specific) predict stronger or weaker effects of gender identity labels on sexual attraction? Most recent models of sexual orientation (e.g. Rosario \& Schrimshaw, 2014) suggest that such external influences should have no effect on sexual attraction, but we predict that sexual orientation and views of gender will influence sexual attraction ratings (see Table 1).

The multiple-item scales for all moderators had adequate reliabilities (all alphas $>=.88$ ). Preliminary analyses showed that they all intercorrelated quite strongly (see Table 3). Thus, we considered treating them as indicators of a single factor. In that analysis, the scree plot showed clear evidence of a single factor. The alpha reliability of the resulting single scale is .92 , and the first (single) factor accounts for $69 \%$ of the total variance. Because of these strong intercorrelations, a much larger sample would be necessary to empirically separate the individual effects of each moderator. For conceptual parsimony and the greater reliability obtained by combining multiple measures, we report moderator analyses using this single factor, computed as a simple equally-weighted combination of the standardized individual moderator scales. Analyses using the individual moderator scales are reported in supplemental materials. We do not intend to introduce a major new construct to the literature, but in this paper we refer to the single factor as gender traditionalism. This term aims to capture what is common among views of gender as essential and unchanging, negativity toward gays, lesbians, and trans people, and adherence to traditional religious views on gender, sexuality, and marriage. 
Table 3

Correlation Matrix and Descriptive Statistics for Moderator Variables

\begin{tabular}{|c|c|c|c|c|c|c|c|c|c|}
\hline & \multicolumn{7}{|c|}{ Correlation Matrix for Moderator Variables } & \multicolumn{2}{|c|}{$\begin{array}{c}\text { Descriptive } \\
\text { Statistics }\end{array}$} \\
\hline & $\underset{\alpha}{\stackrel{\pi}{\infty}}$ & 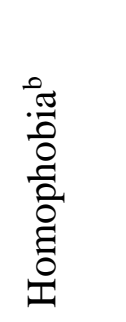 & 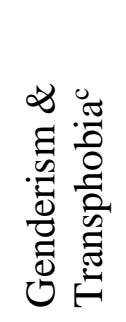 & 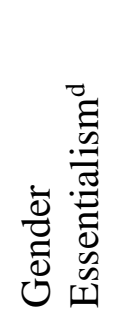 & 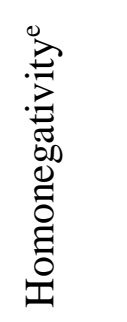 & 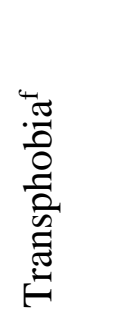 & 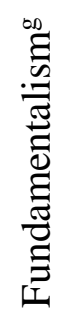 & $\mathrm{M}$ & SD \\
\hline $\mathrm{RWA}^{\mathrm{a}}$ & 1 & & & & & & & 3.28 & 0.96 \\
\hline Homophobia $^{b}$ & 0.661 & 1 & & & & & & 2.26 & 1.00 \\
\hline $\begin{array}{l}\text { Genderism \& } \\
\text { Transphobia }^{c}\end{array}$ & 0.699 & 0.819 & 1 & & & & & 2.60 & 1.07 \\
\hline $\begin{array}{l}\text { Gender } \\
\text { Essentialism }^{\mathrm{d}}\end{array}$ & 0.596 & 0.433 & 0.628 & 1 & & & & 4.22 & 0.92 \\
\hline Homonegativity & 0.753 & 0.710 & 0.753 & 0.676 & 1 & & & 3.14 & 1.26 \\
\hline Transphobia $^{\mathrm{f}}$ & 0.667 & 0.672 & 0.850 & 0.793 & 0.738 & 1 & & 3.53 & 1.03 \\
\hline Fundamentalism ${ }^{\mathrm{g}}$ & 0.722 & 0.486 & 0.488 & 0.439 & 0.504 & 0.411 & 1 & 3.32 & 1.39 \\
\hline
\end{tabular}




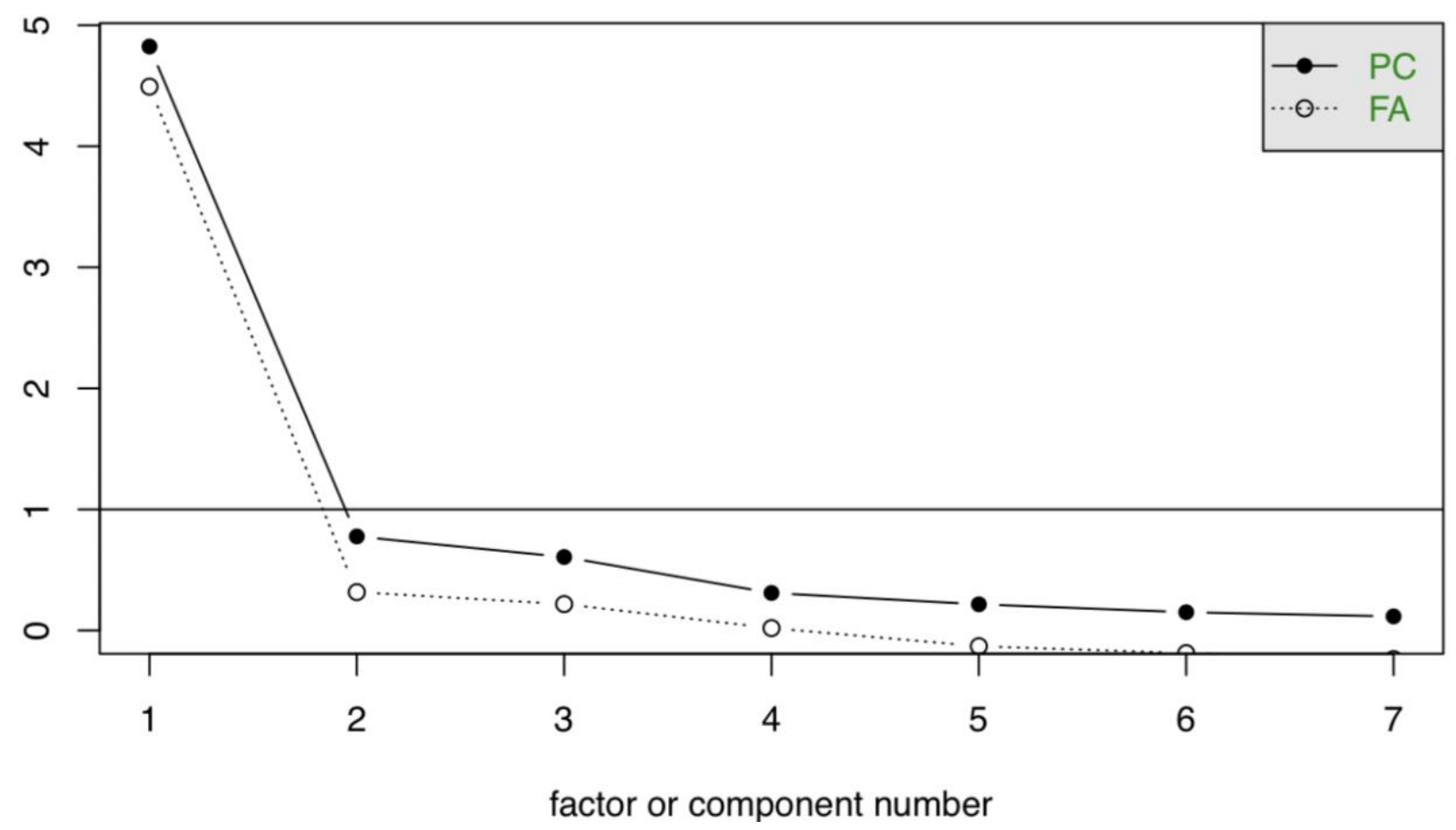

Figure 5. Scree plot from analysis treating individual moderator scales as indicators of an underlying factor.

The analysis of the gender traditionalism moderator had a highly significant three-way interaction of participant gender $*$ label $*$ gender traditionalism; $\mathrm{F}(3,9758.3)=9.697, \mathrm{p}<.001$ (several lower-order interactions were also significant). For male participants, high gender traditionalism predicts slightly lower ratings (approx. 3 points) for cis and trans women targets, moderately lower ratings for non-binary targets (6 points), and slightly higher ratings (2 points) for trans men. For female participants, high gender traditionalism predicts moderately lower ratings ( 7 points) for cis men and non-binary people, and much lower ratings (10-11 points) for trans men and trans women. Potential explanations for these somewhat unexpected patterns are addressed in the general discussion. 
M partic, Moderation by allmods_std

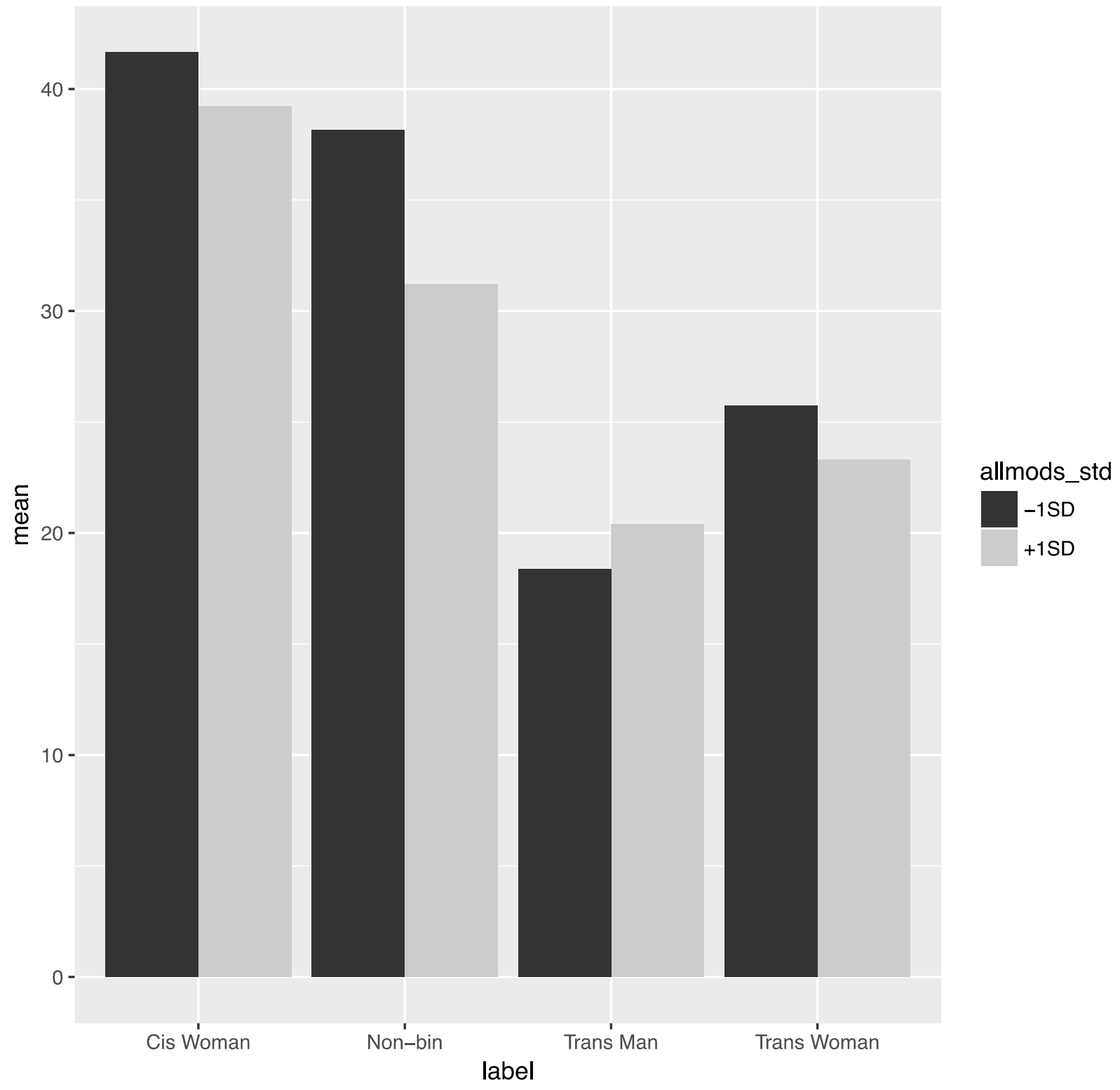

Figure 6. Moderation of label effect on sexual attraction ratings by combined moderator (gender traditionalism) for male participants. 


\section{F partic, Moderation by allmods_std}

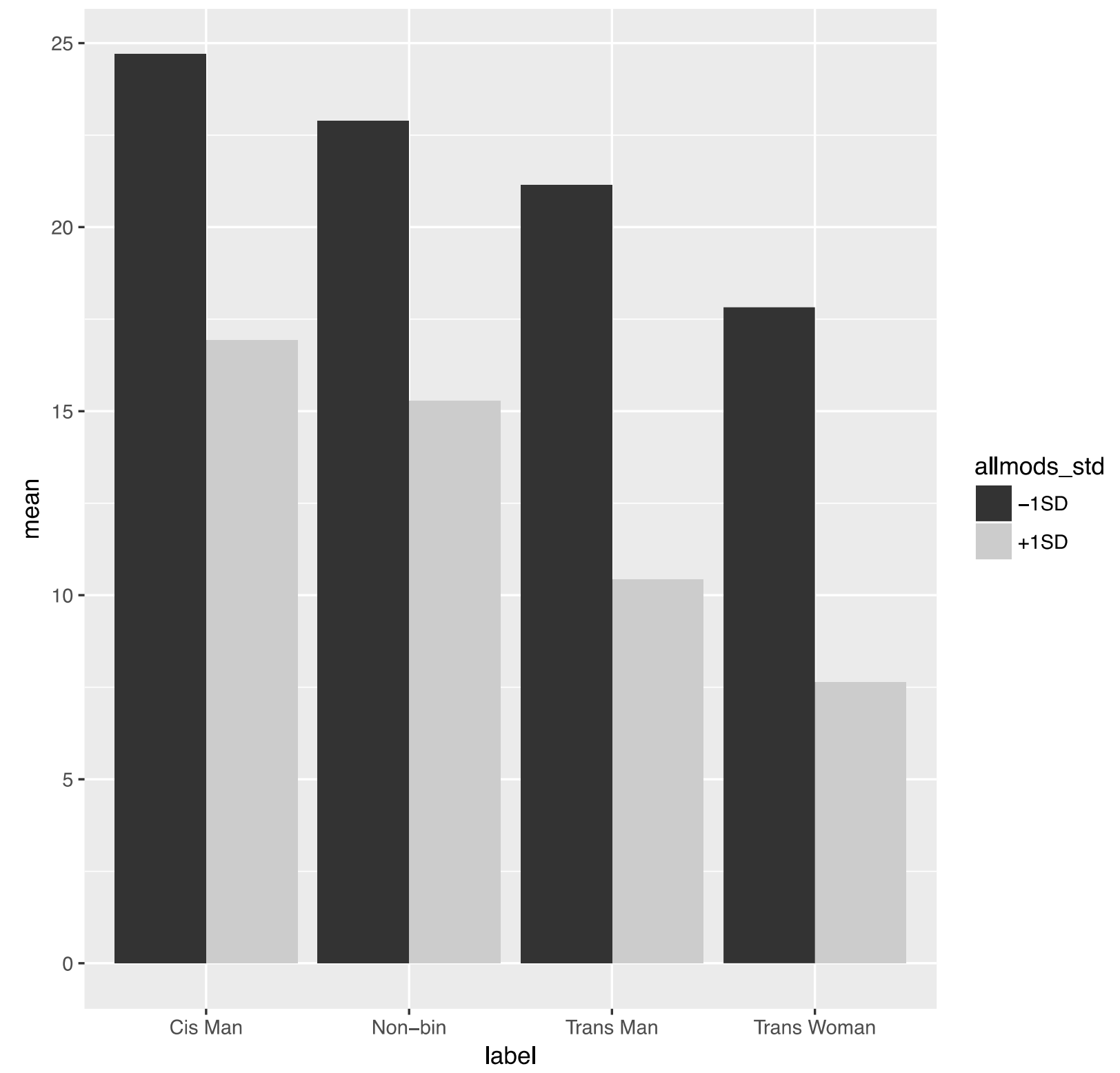

Figure 7. Moderation of label effect on sexual attraction ratings by combined moderator (gender traditionalism) for female participants.

\section{Discussion}

This study sought to disentangle the frequently conflated concepts of gender nonconformity and transgender identity, to examine the unique effects of knowledge about transgender status on perceptions of attractiveness and willingness to become friends. We 
rigorously examined the possibility that a perceiver's belief about a target's transgender status affects perceived attractiveness, and found a strong, pervasive effect of label on ratings of sexual and romantic attraction to exactly the same photos. Attraction ratings were lower for all noncisgender labels, but especially for transgender labels.

Second, our study examined effects of non-binary gender identity along with cisgender and transgender labels. Perceived attractiveness of targets labeled as non-binary almost always fell between reactions to cisgender and transgender targets, supporting the hypothesis that the non-binary label is interpreted as reflecting relatively shallow characteristics (e.g. rejection of gendered appearance and behavior standards), and/or is unfamiliar to participants.

Third, we tested the effect of a composite moderator variable tapping gender traditionalism on sexual attraction. Women (and to some extent men) with high gender traditionalism generally expressed lower attraction for all targets, including cisgender. These systematically lowered ratings may reflect an ideological distaste for the terms "cisgender," "non-binary," and "transgender," because all implicitly legitimize transgender people. Such expressions of negativity toward trans individuals may be a vehicle to express important values and identities, e.g. as religious people or about the appropriate roles of men and women in society (Norton \& Herek, 2013) rather than a neutral assessment of a core sexual orientation. Men high in gender traditionalism also had relatively lower attraction toward cis and trans women, and especially toward non-binary people, which may reflect similar ideological motives as for women. However, men with high gender traditionalism showed an unexpected increase in sexual attraction to transgender men, suggesting that they may perceive less distinction between trans men and trans women, viewing them as a homogenous group. While men low in gender traditionalism rate transgender people as less attractive than cisgender women or non-binary 
people, they do rate trans women as more attractive than trans men, which likely reflects some belief in the legitimacy of transgender people's identities. One explanation for the weaker moderator effects among men is that men's sexual attraction (compared to women's) is more closely linked to a target's sexed appearance (e.g. Bailey et al., 2016), so moderators influence it less.

Fourth, we investigated whether knowledge of transgender status can influence perceptions of gender non-conformity in appearance. Our results showed that this does occur. Participants rated non-binary and transgender targets as less gender-typical (e.g., trans male targets less masculine; trans female targets less feminine) compared to cisgender-labeled targets.

Finally, we varied target race to better approximate the general population; race had no significant main effects or interactions for dependent variables assessing attraction, but did affect masculinity/femininity ratings. Asian and White faces were rated more feminine than Black and Latinx faces, consistent with previous research (e.g. Feliciano et al., 2009; Stolier \& Freeman, 2016) showing that Asian people are stereotyped as feminine while Black people are stereotyped as masculine. This effect suggests that Black trans women may be more likely to be perceived as masculine and/or gender non-conforming than trans women of other races due to the intersection of their gender identity, transgender status, and race. Future research could investigate whether this partially accounts for the greater risk of violence experienced by this group (Adams, 2017; Human Rights Campaign, 2017).

\section{Limitations}

Our participants' responses may not generalize to populations of different cultures, ages, or educational levels, especially to non-cisgender, non-heterosexual populations (a gap which future research should fill). Certain features of the design also limit generalizability. Participants 
knew the photo-rating task was hypothetical, so their responses may not fully predict their behavior. Although we defined all labels at the beginning of the rating task, some results may be influenced by participants' unfamiliarity with the terms (though this same unfamiliarity would likely influence their behavior in an actual dating scenario). Participants also completed the individual difference measures after the photo-rating task, so order effects or fatigue might have influenced their responding.

\section{Implications}

Confirming previous anecdotal discussion, we find that non-binary and trans labels reliably reduce heterosexual perceivers' sexual and romantic attraction to the target individual (compared to a cis label). Sexual and romantic attraction are not solely related to a target's sexed appearance; information about gender identity and transgender status also influences these assessments. For example, our cisgender heterosexual male participants were not equally attracted to all targets with a feminine appearance and female gender identity (cisgender women and transgender women). Nor were they equally attracted to all targets with a feminine appearance assigned female sex at birth (cisgender women and transgender men).

Our findings with respect to the gender traditionalism moderator variable suggest that this decline in attraction is more pronounced for women with highly traditional views of gender, but still present for men with these views. Notably, these highly gender traditional participants reported lower sexual attraction to all targets, possibly reflecting our use of terminology that implicitly legitimizes transgender identities (i.e. "cisgender"). This might also reflect a view that casual sex (as implied by the idea of dating websites) is morally wrong.

Thus, we do not believe that our findings are consistent with the idea that sexual attraction (at least as self-reported) is a straightforward reflection of sexual orientation. Rather, 
these findings support the idea that sexual and romantic attraction are culturally mediated, including influence from prejudice toward an outgroup. Conventional conceptualizations of sexual orientation may be inadequate to deal with such a situation.

Our findings highlight questions about at least two underlying theoretical assumptions about the nature of sexual and romantic attraction; first, that sexual attraction is "oriented" to some essential facet of gender (e.g. Rosario \& Schrimshaw, 2014; Bailey et al., 2016), and second, that there are two and only two types of gender to "orient" towards, maleness and femaleness. These assumptions have been critiqued elsewhere (e.g. van Anders, 2015), but empirical research on which to base new models is intensely needed, as current models of sexual orientation do not adequately articulate how sexed appearance, gender identity, and transgender status interact to influence perceptions of attractiveness.

Future research should examine what specific factors do influence attraction to people with various gender identity labels. For example, what stereotypic assumptions or attributions do perceivers make about someone with a non-binary or trans identity that might influence their level of attraction? Such research could also explore the interactions of label with the gender typicality of facial appearance - a factor that we explicitly held constant in our study to avoid the common conflation of trans status with gender-atypical appearance. Future research might also pursue our finding that women in particular are equally willing to befriend non-binary and trans people as cis people. Does friendship or acquaintanceship with someone having a particular gender identity reduce stereotyping and prejudice, as it robustly does in other intergroup situations (Pettigrew \& Tropp, 2006)? Might an initial nonromantic friendship create the conditions for the later emergence of sexual and romantic attraction? 
This study adds to a sparse literature on perception of transgender and non-binary individuals, and we hope it encourages other scholars to include these groups in their work on attraction and social perception. Increased research can improve the day-to-day lives of gender minorities, while also adding depth to existing theories of sexual and romantic attraction. 
GENDER LABELS AND ATTRACTIVENESS 31

\section{References}

Abbey, A. (1982). Sex differences in attributions for friendly behavior: Do males misperceive females’ friendliness? Journal of Personality and Social Psychology, 42(5), 830-838. http://doi.org/10.1037/0022-3514.42.5.830

Adams, N. (2017, September 14). GLAAD calls for increased and accurate media coverage of transgender murders. Retrieved from https://www.glaad.org/blog/glaad-calls-increased$\underline{\text { and-accurate-media-coverage-transgender-murders }}$

Altemeyer, B., \& Hunsberger, B. E. (2004). A revised religious fundamentalism scale: The short and sweet of it. The International Journal for the Psychology of Religion, 14(1), 47-54.

American Civil Liberties Union (ACLU). (2017). G.G. v. Gloucester County School Board. Retrieved from https://www.aclu.org/cases/gg-v-gloucester-county-school-board

Bailey, J. M., Vasey, P. L., Diamond, L. M., Breedlove, S. M., Vilain, E., \& Epprecht, M. (2016). Sexual Orientation, Controversy, and Science. Psychological Science in the Public Interest, 17(2), 45-101. http://doi.org/10.1177/1529100616637616

Bame, Y. (2017, May 17). 21\% of Americans believe that being transgender is a mental illness. Retrieved from https://today.yougov.com/news/2017/05/17/21-americans-believeidentifying-transgender-menta/

Belawski, S.E. \& Sojka, C.J. (2014). Intimate relationships. In Erickson-Schroth, L. (Ed.), Trans bodies, trans selves: A resource for the transgender community (pp. 335-355). Oxford, England: Oxford University Press.

Berman, M., \& Phillips, A. (2017, March 30). North Carolina governor signs bill repealing and replacing transgender bathroom law amid criticism. The Washington Post. Retrieved 
GENDER LABELS AND ATTRACTIVENESS 32

from https://www.washingtonpost.com/news/post-nation/wp/2017/03/30/north-carolina-

lawmakers-say-theyve-agreed-on-a-deal-to-repeal-the-bathroom-bill/

Bettcher, T. M. (2007). Evil deceivers and make-believers: On transphobic violence and the politics of illusion. Hypatia, 22(3), 43-66. doi:10.1111/j.1527-2001.2007.tb01090.x

Bissinger, B., \& Leibovitz, A. (2015, July). Caitlyn Jenner: The full story. Vanity Fair. Retrieved from https://www.vanityfair.com/hollywood/2015/06/caitlyn-jenner-bruce-cover-annie$\underline{\text { leibovitz }}$

Bleske-Rechek, A., Somers, E., Micke, C., Erickson, L., Matteson, L., Stocco, C., \& Ritchie, L. (2012). Benefit or burden? Attraction in cross-sex friendship. Journal of Social and Personal Relationships, 29(5), 569-596. http://doi.org/10.1177/0265407512443611

Ching, B. H. H., \& Xu, J. T. (2017). The effects of gender neuroessentialism on transprejudice: An experimental study. Sex Roles, 1-14. http://doi.org/10.1007/s11199-017-0786-3

Dank, M., Lachman, P., Zweig, J. M., \& Yahner, J. (2014). Dating violence experiences of lesbian, gay, bisexual, and transgender youth. Journal of Youth and Adolescence, 43(5), 846-857. http://doi.org/10.1007/s10964-013-9975-8

Factor, R., \& Rothblum, E. (2008). Exploring gender identity and community among three groups of transgender individuals in the United States: MTFs, FTMs, and genderqueers. Health Sociology Review, 17, 235-253. http://dx.doi.org/10.5172/hesr.451.17.3.235

Feliciano, C., Robnett, B., \& Komaie, G. (2009). Gendered racial exclusion among white internet daters. Social Science Research, 38(1), 39-54. http://doi.org/10.1016/j.ssresearch.2008.09.004 
Flores, A.R., Herman, J.L., Gates, G.J., \& Brown, N.T. (2016). How many adults identify as transgender in the United States? Los Angeles, CA: Williams Institute. Retrieved from http://williamsinstitute.law.ucla.edu/wp-content/uploads/How-Many-Adults-Identify-asTransgender-in-the-United-States.pdf

Galinsky, A. D., Hall, E. V., \& Cuddy, A. J. C. (2013). Gendered races: Implications for interracial marriage, leadership selection, and athletic participation. Psychological Science, 24(4), 498-506. http://doi.org/10.1177/0956797612457783

Galupo, M. P., Lomash, E., \& Mitchell, R. C. (2017). “All of My Lovers Fit Into This Scale”: Sexual Minority Individuals' Responses to Two Novel Measures of Sexual Orientation. Journal of Homosexuality, 64(2), 145-165. http://doi.org/10.1080/00918369.2016.1174027

Garfinkel, H. (1967). Studies in Ethnomethodology. Englewood Cliffs, N.J.: Prentice-Hall.

Gerhardstein, K., \& Anderson, V. (2010). There's more than meets the eye: Facial appearance and evaluations of transsexual people. Sex Roles, 63, 361-373.

Glick, P., \& Whitehead, J. (2010). Hostility toward men and the perceived stability of male dominance. Social Psychology, 41(3), 177-185. http://doi.org/10.1027/1864-9335/a000025

Graham, J., Nosek, B.A., Haidt, J., Iyer, R., Koleva, S., \& Ditto, P. H. (2011). Mapping the moral domain. Journal of Personality and Social Psychology, 101(2), 366-85. http://doi.org/10.1037/a0021847

Haupert, M. (2016). Preliminary gender essentialism scale. Unpublished manuscript, Indiana University, Bloomington, IN.

Hill, D., \& Willoughby, B. (2005). The development and validation of the Genderism and Transphobia Scale. Sex Roles, 53(7-8). doi:10.1007/s11199-005-7140-x. 
GENDER LABELS AND ATTRACTIVENESS 34

Human Rights Campaign. (2017, September 2014). Violence against the Transgender Community in 2017. Retrieved from https://www.hrc.org/resources/violence-against-thetransgender-community-in-2017

James, S. E., Herman, J. L., Rankin, S., Keisling, M., Mottet, L., \& Anafi, M. (2016). The Report of the 2015 U.S. Transgender Survey. Washington, DC: National Center for Transgender Equality.

Judd, C. M., Westfall, J., \& Kenny, D. A. (2012). Treating stimuli as a random factor in social psychology: A new and comprehensive solution to a pervasive but largely ignored problem. Journal of Personality and Social Psychology, 103(1), 54-69.

Kessler, S. J., \& McKenna, W. (1978). Gender: An ethnomethodological approach. Chicago, IL: University of Chicago Press.

Kuper, L. E., Nussbaum, R., \& Mustanski, B. (2012). Exploring the diversity of gender and sexual orientation identities in an online sample of transgender individuals. Journal of Sex Research, 49(2-3), 244-254. http://doi.org/10.1080/00224499.2011.596954

Lee, C., \& Kwan, P. (2014). The trans panic defense: Masculinity, heteronormativity, and the murder of transgender women. Hastings Law Journal, 66(1), 77-132. http://doi.org/10.2139/ssrn.2430390

Ma, D., Correll J., \& Wittenbrink, B. (2015). The Chicago Face Database: A free stimulus set of faces and norming data. Behavior Research Methods, 47, 1122-1135.

Manganelli Rattazzi, A. M., Bobbio, A., \& Canova, L. (2007). A short version of the Right-Wing Authoritarianism (RWA) Scale. Personality and Individual Differences, 43(5), 1223-1234. http://doi.org/10.1016/j.paid.2007.03.013 
Martinez, J. H., Smith, G.A., Cooperman, A., Mohamed, B., Alper, B.A., Sciupac, E.P., Gecewicz, C., Bertoni, N., McGeeney, K., Hatley, N., Stencel, S., Lipka, M., Sandstrom, A., Webster, B., Rosenberg, S., Mitchell, T., Schiller, A., \& Cornibert, S.S. (2016, September 26). Where the Public Stands on Religious Liberty vs. Nondiscrimination. Washington, DC: Pew Research Center. Retrieved from http://assets.pewresearch.org/wp-content/uploads/sites/11/2016/09/Religious-Libertyfull-for-web.pdf

Morrison, M.A., \& Morrison, T.G. (2003). Development and validation of a scale measuring modern prejudice toward gay men and lesbian women. Journal of Homosexuality, 43(2), $15-37$.

Nagoshi, J., Adams, K., Terrell, H., Hill, E., Brzuzy, S., \& Nagoshi, C. (2008). Gender differences in correlates of homophobia and transphobia. Sex Roles, 59(7/8), 521-531. doi:10.1007/s11199-008-9458-7

Nagoshi, J. L., Nagoshi, C. T., Terrell, H. K., \& Brzuzy, S. (2014). The complex negotiations of gender roles, gender identity, and sexual orientation among heterosexual, gay/lesbian, and transgender individuals. Journal of Ethnographic \& Qualitative Research, 8, 205221.

Norton, A., \& Herek, G. (2013). Heterosexuals' attitudes toward transgender people: findings from a national probability sample of U.S. adults. Sex Roles, 68(11/12), 738-753. doi:10.1007/s11199-011-0110-6

OkCupid. (2017, September 14). Orientation, Gender, and Non-Binary Profile Options. Retrieved from https://okcupid.desk.com/customer/en/portal/articles/2202154orientation-gender-and-non-binary-profile-options 
Pettigrew, T. F., \& Tropp, L. R. (2006). A meta-analytic test of intergroup contact theory. Journal of Personality and Social Psychology, 90(5), 751-783. http://doi.org/10.1037/0022-3514.90.5.751

Rosario, M. \& Schrimshaw, E.W. (2014). Theories and etiologies of sexual orientation. In D.L. Tolman \& L.M. Diamond (Eds.). APA Handbook of Sexuality and Psychology: Vol. 1 Person-Based Approaches. (p. 555- 596). Washington, DC: American Psychological Association. http://dx.doi.org/10.10371/14193-018.

Sell, R. L. (1997). Defining and measuring sexual orientation: a review. Archives of Sexual Behavior, 26(6), 643-58. Retrieved from http://www.ncbi.nlm.nih.gov/pubmed/9415799

Serano, J. (2007). Whipping girl: A transsexual woman on sexism and the scapegoating of femininity. Berkeley, CA: Seal Press.

Steinmetz, K. (2014, May 29). The transgender tipping point. Time. Retrieved from http://time.com/135480/transgender-tipping-point/

Stern, C., \& Rule, N. O. (2017). Physical Androgyny and Categorization Difficulty Shape Political Conservatives' Attitudes Toward Transgender People. Social Psychological and Personality Science, 109, 194855061770317-8.

http://doi.org/10.1177/1948550617703172

Stolier, R. M., \& Freeman, J. B. (2016). Neural pattern similarity reveals the inherent intersection of social categories. Nature Neuroscience, 19(6), 795-797. http://doi.org/10.1038/nn.4296

Tate, C. C., Youssef, C. P., \& Bettergarcia, J. N. (2014). Integrating the study of transgender spectrum and cisgender experiences of self-categorization from a personality perspective. Review of General Psychology, 18(4), 302-312. 
van Anders, S. M. (2015). Beyond Sexual Orientation: Integrating Gender/Sex and Diverse Sexualities via Sexual Configurations Theory. Archives of Sexual Behavior (Vol. 44). Springer US. http://doi.org/10.1007/s10508-015-0490-8

Walch, S. E., Ngamake, S. T., Francisco, J., Stitt, R. L., \& Shingler, K. a. (2012). The attitudes toward transgendered individuals scale: psychometric properties. Archives of Sexual Behavior, 41(5), 1283-91. http://doi.org/10.1007/s10508-012-9995-6

Westfall, J., Kenny, D. A., \& Judd, C. M. (2014). Statistical power and optimal design in experiments in which samples of participants respond to samples of stimuli. Journal of Experimental Psychology, 143(5), 2020-2045.

Wilkins, C. L., Chan, J. F., \& Kaiser, C. R. (2011). Racial stereotypes and interracial attraction: phenotypic prototypicality and perceived attractiveness of Asians. Cultural Diversity \& Ethnic Minority Psychology, 17(4), 427-31. http://doi.org/10.1037/a0024733

Wodda, A., \& Panfil, V. (2015). "Don't talk to me about deception": The necessary erosion of the trans* panic defense. Albany Law Review, 78(3), 927-971. http://doi.org/10.1017/CBO9781107415324.004

Wolff, M., Wells, B., Ventura-DiPersia, C., Renson, A., \& Grov, C. (2017). Measuring Sexual Orientation: A Review and Critique of U.S. Data Collection Efforts and Implications for Health Policy. Journal of Sex Research, 54(4-5), 507-531. http://doi.org/10.1080/00224499.2016.1255872

Worthen, M. G. F. (2013). An Argument for Separate Analyses of Attitudes Toward Lesbian, Gay, Bisexual Men, Bisexual Women, MtF and FtM Transgender Individuals. Sex Roles, 68, 703-723. http://doi.org/10.1007/s11199-012-0155-1 
Wright, L. W., Adams, H. E., \& Bernat, J. (1999). Development and validation of the homophobia scale. Journal of Psychopathology and Behavioral Assessment, 21(4), 337347. 